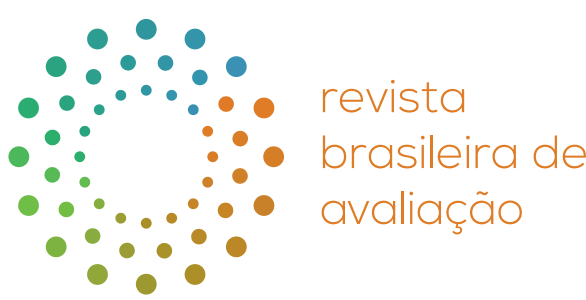

\title{
Desafios contemporâneos da avaliação em saúde: A trajetória reflexiva de Oswaldo Yoshimi Tanaka
}

\section{Contemporary challenges of health evaluation: the reflective trajectory of Oswaldo Yoshimi Tanaka}

\author{
Marco Akerman ${ }^{1 *}$ (branco) (D) \\ ${ }^{1}$ Universidade de São Paulo (USP), Faculdade de Saúde Pública, Departamento de Política Gestão e Saúde, São Paulo, SP, \\ Brasil
}

COMO CITAR: Akerman, Marco (2022). Desafios contemporâneos da avaliação em saúde: A trajetória reflexiva de Oswaldo Yoshimi Tanaka. Revista Brasileira de Avaliação, 11(1), e110322. https://doi.org/10.4322/ rbaval202211003

\section{Resumo}

Quem trabalha com avaliação precisa o exercício de para que e para quem estamos fazendo avaliação. Assim, para que a avaliação influencie políticas de saúde, será importante considerar que não basta um bom método e análise estatística robusta. Essas podem facilitar a publicar o artigo científico, mas sem necessariamente influenciar a tomada de decisão. "Enquanto estiver na ativa, quero constantemente problematizar para que e para quem está servindo a avaliação". Com graduação Medicina pela Universidade de São Paulo (1971), mestrado (1983) doutorado (1988) e livre-docência (1994) em Saúde Pública pela Universidade de São Paulo, Oswaldo Tanaka é professor titular do Departamento de Política, Gestão e Saúde da Faculdade de Saúde Pública da USP desde 2003. Membro do GT de Monitoramento e Avaliação da ABRASCO, Tanaka tem se dedicado à pesquisa e à docência no campo da avaliação de política e gestão em saúde. Nesta entrevista o professor lembra sua trajetória para se tornar um avaliador e aborda alguns dos principais desafios da prática da avaliação.

Palavras-chave: Avaliação em saúde. Teorias em avalição. Metodologias em avaliação.

\section{Abstract}

Those who work with evaluation need the exercise of what and for whom we are doing evaluation. Thus, for the evaluation to influence health policies, it will be important to consider that a good method and robust statistical analysis are not enough. These can facilitate the publication of the scientific article, but without necessarily influencing decision-making. "While I'm active, I want to constantly problematize what and for whom the evaluation is serving". With a degree in Medicine from the University of São Paulo (1971), a master's degree (1983), a doctorate (1988) and a professorship (1994) in Public Health from the University of São Paulo, Oswaldo Tanaka is a professor at the Department of Policy, Management and Health at Faculty of Public Health at USP since 2003. A member of the Monitoring and Evaluation Working Group at ABRASCO, Tanaka has been dedicated to research and teaching in the field of health policy and management evaluation. In this interview, the professor recalls his trajectory to become an evaluator and addresses some of the main challenges of the evaluation practice.

Keywords: Health evaluation. Theories under evaluation. Methodologies in evaluation.
A RBAVAL apoia os esforços relativos à visibilidade dos autores negros na produção científica. Assim, nossas publicações solicitam a autodeclaração de cor/etnia dos autores dos textos para tornar visível tal informação nos artigos.

Recebido: Janeiro 19, 2022

Aceito: Janeiro 20, 2022

*Autor correspondente:

Marco Akerman

E-mail: marco.akerman@gmail.com

\section{(cc) BY}

Este é um artigo publicado em acesso aberto (Open Access) sob a licença

Creative Commons Attribution, que permite uso, distribuição e reprodução em qualquer meio, sem restrições desde que o trabalho original seja corretamente citado. 


\section{Revista: Há quanto tempo você estuda, pesquisa e dá aula sobre avaliação? Como começou sua história com este tema?}

Tanaka: Iniciei minha trajetória estudando e trabalhando em planejamento e programação em saúde materno-infantil. A inquietude decorrente das dificuldades em implementar os planejamentos me fez interessado em avaliação. O primeiro trabalho nesse campo foi o mestrado em que avaliei o programa de saúde da criança da SES realizado no período de 1975 a 1979. Tive ainda a oportunidade de estudar em Bristol, no Reino Unido, e de conhecer o sistema de saúde inglês. Após a minha inserção na FSP-USP em 1981, comecei e estudar mais profundamente avaliação. Tendo avaliado a utilização de uma unidade básica de saúde atrelada a um serviço de pronto atendimento, na perspectiva do usuário, em meu doutorado, fortaleci meu interesse por avaliação.

\section{Então seu trabalho com avaliação começa nos anos $1980 ?$}

Comecei meu trabalho profissional como pediatra clínico. Após a minha residência no Chile em Pediatria Social [eu estava lá no meio do golpe e passava tanque na porta da minha casa; tinha toque de recolher], me interessei pela lógica de sistema. Em 1974 o Chile tinha o melhor sistema de saúde da América Latina.

Naquele ano de 1974, a OPAS tinha uma residência médica chamada "Residência de Pediatria Social", para toda América Latina. E ali eu tive uma coisa que me chamou muito a atenção, que foi a forma como o sistema era estruturado: existia um médico e uma enfermeira em todos os rincões do país. E eu atendia o tempo todo. Fazia plantão de pediatria a cada três dias no hospital. A residência era totalmente prática, e você tinha que fazer tudo, da história clínica ao raio-x. E isso me deu uma dimensão diferente do que era atenção à criança.

Quando eu voltei ao Brasil, o meu primeiro emprego foi no Centro de Saúde Escola da Faculdade de Medicina de Santo Amaro, mas rapidamente eu fui contratado como supervisor da saúde da criança na SES, e aí é que eu entendi a programação; isso me deu o primeiro degrau para entender assistência de uma forma mais integrada, sistemática. Em 1978 eu entrei no mestrado. Meu orientador foi o professor Cornélio Pedroso Rosenburg. Ele era secretário municipal de Saúde de São Paulo e foi ele que posteriormente me convidou a ser professor assistente, tempo parcial, do Departamento de Saúde Materno-Infantil. Minha dissertação foi "Avaliação do Programa de Saúde da Criança do Estado de São Paulo", usando essencialmente dados quantitativos do sistema de informação, trabalhando cobertura e concentração de atividades e algumas informações de resultados. Foi quando eu aprofundei um pouco o conhecimento sobre as ações de saúde, lendo Boltanski. Olhando a questão de como o padrão proposto pelos programas era muito mais de classe média para classe baixa, comecei a entender que coisas básicas como o calendário de vacinação eram facilmente cumpridas, mas as outras, de acompanhamento de crescimento, alimentação e tal, enfrentavam muito mais dificuldade. Foi nesse momento que eu comecei a achar que a minha leitura tinha que ter outro tipo de desenvolvimento.

\section{E o que ajudou a ampliar ou a aprofundar sua leitura?}

Em 1980, eu fui para o Departamento de Epidemiologia na Universidade de Bristol. Foi a formação educacional mais importante que eu tive na minha vida. Depois de 4 meses, meu orientador, John Colley, me perguntou: "Você conhece o General Practitioner? Então, você vai ficar 40 dias vivendo com ele. Você vai ficar com ele 24 horas por dia, durante 40 dias".

Os médicos generalistas (GP) tinham a obrigação de fazer visita domiciliar que acontecia com frequência, ele fazia visita domiciliar de manhã e atendia à tarde. Ele tinha o consultório na casa dele. Ele começava a atender e uma enfermeira do distrito acompanhava a população na área. Ela conversava com as pessoas antes da consulta e fazia uma triagem. A enfermeira não era funcionária dele, mas do distrito de saúde, que a apoiava com carro e custeio das visitas. Ela era funcionária do estado e trabalhava com o médico.

${ }^{1}$ Luc Boltanski é um sociólogo francês, nascido em 1940. OT se refere ao seu livro As classes sociais e o corpo. 


\section{Que outros aprendizados você teve nesse contato com o GP?}

A maneira como ele recebia seu pagamento pelo trabalho era interessante. Ele recebia por captação. O usuário levava o contrato, conversava com ele, e ele assinava, e o contrato voltava ao distrito; ele recebia também por vacina, palestra, mas o compromisso de atender e visitar fazia parte do contrato. Os usuários tinham toda a liberdade de dizer ao GP: "Não quero mais você" e levavam de volta o contrato ao distrito para buscar outro GP; era uma relação construída com clareza entre as partes. Para mim foi uma lição.

\section{E como seguiu essa sua observação?}

Depois de quatro meses, meu orientador me perguntou então o que eu queria ver depois daquela experiência. E eu disse que queria ver se o GP trabalha bem, como é que ele faz com vacina, alimentação, crescimento e desenvolvimento, se ele mede peso, altura, perímetro cefálico, perímetro torácico, tudo que eu tinha aprendido na Pediatria. Colley disse: "tá bom, mas para você fazer a análise, você precisa de uma comparação, existe um médico chamado Clinical Medical Officer no distrito, que é um pediatra especializado. Vá conhecê-lo". Fiquei uma semana com esse pediatra especializado pra entender que o GP é um cara mais abrangente, atende todo mundo, ele é o médico da família, e o outro é um especialista, um pediatra.

\section{E como essa estada na Inglaterra te ajudou no seu mestrado?}

A minha dissertação de mestrado era de uma forma um pouco diferente, do que eu observei na Inglaterra, porque eu analisei toda a programação de saúde da criança só com dados quantitativos, mas para mim foi importantíssimo, porque reuniu-se a experiência do Chile com a especialização da Inglaterra. Reuniu-se uma coisa que penso ser a melhor forma de formar um pesquisador, fazendo perguntas.

\section{E o que aconteceu a seguir?}

Com a defesa do mestrado, eu assumi outros cargos na Secretaria de Estado de São Paulo, da supervisão de saúde da criança e fui nomeado assistente da Coordenadoria de Saúde da Comunidade, cujo coordenador era o prof. Eurivaldo Sampaio de Almeida. Aí eu pude expandir o acompanhamento para todos os programas médico-sanitários da SES. Já no doutorado, entrei na área de supervisão de todos os programas de saúde da comunidade do estado de São Paulo. Fui então convidado para ser assistente técnico de direção na Secretaria Municipal de Saúde quando o prof. Guedes ${ }^{2}$ assumiu como secretário de saúde. E nesse momento desenhei meu doutorado para avaliar como a população utilizava o Centro de Saúde (unidade básica) e o Pronto Atendimento. Eu fiz um desenho para tentar entender qual era o motivo da busca entre o Centro de Saúde e o Pronto Atendimento. Escolhi a UBS do Jardim São Jorge, que foi o primeiro local em que a gente montou o Pronto Atendimento. Por exemplo, mãe com criança menor de 5 anos, porque vinha no PA, e tentar entender como é que eles usavam um e outro serviço no mesmo local. Esse doutorado me permitiu entender outra lógica, que é a lógica da oferta e uso de serviço. Aí ficou claro que as mães de menores de 5 anos usavam o Centro de Saúde quando precisavam de alguma coisa como vacinação - aquela época dava leite também. Mas quando ela precisava de algum outro problema que era agravo de saúde ela ia a um Pronto Atendimento porque ali ela tinha acesso a raio-x e a um encaminhamento, etc.

Isto me fez compreender que a demanda é definida pela oferta. E que a população é muito inteligente. Ela é capaz de identificar o que se oferece, e ela vai buscar os serviços em cima daquilo que ela interpreta como necessidade, e que o serviço oferece.

\section{Você falou do Boltanski, da epidemiologia descritiva, do seu orientador, etc. Quais outros autores te influenciaram no doutorado no mestrado?}

O autor que mais me influenciou foi Avedis Donabedian ${ }^{3}$ que propunha as dimensões de estrutura, processo e resultado, que era totalmente compatível com o programa de saúde da criança da SES,

\footnotetext{
2 José da Silva Guedes, médico-sanitarista, professor da Faculdade de Ciências Médicas da Santa Casa de São Paulo. Foi secretário da Saúde do município de São Paulo (1983-1985) e secretário da Saúde do Estado de São Paulo (1995- 2002).

3 Avedis Donabedian, médico, nasceu em Beirute, no Líbano. Desenvolveu interesse na qualidade da assistência à saúde e estudou administração de serviços e epidemiologia na Universidade de Harvard. Ele passou o resto
} 
cuja base era o planejamento normativo CENDES-OPS. Acredito que durante a minha trajetória de executar avaliações de serviços e sistemas de saúde, seja no setor público ou no setor privado, a avaliação foi sendo baseada em distintos referenciais teóricos.

No início, tendo em vista o planejamento normativo, o foco principal foi na abordagem quantitativa com referencial de Donabedian com os componentes de estrutura, processo e resultado e Guba \& Lincoln ${ }^{4}$. Esses últimos permitiram incorporar a abordagem qualitativa com ênfase no sujeito social em que pela experiência empírica concreta aporta detalhes subjetivos de grande significado para entender a interação produzida nas ações de saúde. Outras referências foram: Mary-Jane Spink, Cecília Minayo, Bardin. Essas referências me permitiram desenvolver abordagens quanti-quali sequenciais em avaliação, iniciando pela abordagem quantitativa, já que o SUS dispõe de uma quantidade imensa de dados que podem ser transformados em informação por meio de boas análises.

Esta forma de avaliar permite que haja melhor especificação da pergunta avaliativa que direciona a coleta e análise de dados na abordagem qualitativa e permite a escolha de informantes-chave que foram identificados na abordagem quantitativa, tendo como referência Creswell ${ }^{5}$. Atualmente, as complexidades das políticas de saúde têm mudado paulatinamente o papel do Estado visando a eficiência na utilização dos recursos públicos. Esta mudança tem resultado na não responsabilização direta pelo poder público no provimento dos serviços essenciais. Como consequência, trouxe para avaliação novos desafios na medida em que o foco, a forma e a metodologia não são mais suficientes para influenciar a tomada de decisão. Entendo que a abordagem quanti-quali continua sendo a mais adequada de forma sequencial, mas a abordagem qualitativa pode ser explorada tendo como referencial a ciência da implementação mais condizente com o estágio atual dos sistemas de saúde. Para tanto se propõe a análise nas dimensões de Política, ator social, estratégias e contexto, o que permitirá estratificar os resultados, visando o julgamento de valor em cada uma dessas dimensões que têm distintas características de mobilização de recursos, sejam humanos, materiais ou financeiros.

\section{Em seu mestrado, você pesquisou quem planeja os serviços e, no doutorado, quem oferece. Mas também olhou quem utiliza os serviços, não é isso?}

Isso! No mestrado eu olhei de dentro para fora, no doutorado me permitiu olhar de fora para dentro. Então, por que eu digo isso? Porque alguns textos que eu li na Inglaterra, tipo Susser ${ }^{6}$, só começaram a ter significado para mim na hora que eu comecei meu doutorado. E para mim, referências importantes, sem dúvida, foram Donabedian, tudo que ele escreveu; Outra referência para mim foram Guba e Lincoln, que trouxeram a questão da avaliação de quarta geração, valorizando a incorporação do componente participativo na avaliação. Não são minhas únicas referências, mas são aquelas que permitiram ter uma capacidade de enxergar avaliação com outros olhos.

\section{A sua primeira orientação foi para algum trabalho de avaliação?}

Sim, a primeira orientação foi um trabalho de avaliação. No começo me interessava por avaliação no geral: eu fiz avaliação de UTI, avaliação de tudo em relação à criança. Fiz avaliação de programas de atendimento, fiz alguma coisa na área de doenças crônicas e doenças infecciosas em crianças. E comecei a orientar, a partir de 1984, quando terminei meu doutorado. Uma das pessoas que me impulsionou muito foi a Cristina Melo, que veio trazer uma preocupação, de como é que ela poderia avaliar a Atenção Básica. Ela é docente da Escola de Enfermagem da UFBA, e foi a pessoa que me ajudou a escrever o livro vermelho: Avaliação de Programas de Saúde do Adolescente: um modo de fazer. ${ }^{16}$ Nessa época eu tinha uma relação muito forte com a OPAS e tínhamos aqui um curso de especialização em Saúde Materno-Infantil, financiado pela OPAS, em conjunto com a Universidade de Medellín. Eu coordenava os cursos que aconteciam aqui no Brasil, e dava aulas de avaliação em Medellín.

de sua vida profissional nos EUA divulgando os conceitos de qualidade, que se tornou a sua marca, a Tríade de Donabedian: estrutura, processo e resultado.

${ }^{4}$ Egon G. Guba e Yvonna S. Lincoln cunharam o termo "avaliação de quarta geração" que representou uma mudança importante na atividade de avaliação. A avaliação de quarta geração, uma abordagem mais fundamentada e esclarecida, transcende a ciência para incluir uma miríade de elementos humanos, políticos, sociais, culturais e contextuais.

5 John W. Creswell é um acadêmico americano conhecido por seu trabalho em pesquisa de métodos mistos.

6 Mervyn Wilfred Susser era um ativista, médico e epidemiologista sul-africano. Ele é considerado um dos pioneiros da epidemiologia no século XX. 


\section{Qual era a sua concepção de avaliação no livro Avaliação de Programas de Saúde do Adolescente: um modo de fazer?}

A ideia foi tornar a avaliação um instrumento do cotidiano. Ele dava dica, como fazer, tinha exemplos de indicadores, exemplos de técnica, o que é um grupo focal, o que é entrevista semiestruturada, com a ideia de que cada um aproveitasse parte do livro para fazer alguma avaliação. Quero lembrar um detalhe que, no começo da década de 2000, ficou muito forte um sentimento de que a avaliação deveria ser uma especialidade. Desse movimento resultou em mestrados profissionais em avaliação, acompanhando a lógica americana do American Evaluation Association. Eu, pessoalmente, tenho defendido que a avaliação não deveria ser uma especialidade. Parto do princípio de que ela deve ajudar na tomada de decisão, eu digo que para complexidade do setor saúde todo mundo toma decisão, então, avaliação não deve ser uma coisa de especialista. Essa é uma posição minha, que eu mantenho até hoje, mas não é consenso no grupo dos que estudam e trabalham com avaliação.

\section{E como foi essa sua maior aproximação com as ciências qualitativas?}

Uma pesquisa desenvolvida por minha aluna de doutorado, a médica pediatra Edith Lauridsen Ribeiro, ela buscava entender a capacidade dos médicos pediatras em abarcar a questão de crescimento e desenvolvimento de uma lógica mais abrangente e não apenas o crescimento biológico e desenvolvimento psicomotor. Para aprofundar esta questão, fomos em busca de entender a representação social. Na busca deste conhecimento o livro que mais me impactou foi o da Mary-Jane Spink, da Psicologia Social da PUC. Eu a conhecia e tomei a liberdade de pedir para para acompanhar o grupo da Psicologia Social na PUC, junto com os alunos de pós-graduação dela. Aprendi muito e utilizo na avaliação.

No livro de saúde do adolescente eu já defendia quanti e quali. Nas etapas do meu mestrado e do meu doutorado eu havia usado muitos dados quantitativos, mas essas vertentes não me deixavam completamente satisfeito com o que eu estava analisando. Fui entendendo que precisava incorporar o qualitativo para avançar na avaliação em saúde. Eu aprendi com a Mary-Jane Spink que a coisa mais importante na abordagem qualitativa é a escolha do informante-chave, com a seguinte definição: informante-chave não é simplesmente uma pessoa que está na estrutura com uma hierarquia, alguma responsabilidade, em realidade é aquele que pela sua vivência empírica concreta, tem uma informação da qual você não dispõe em nenhum lugar, uma informação crucial para entender a interação.

No trabalho da Edith no Centro de Saúde no Butantã, a gente tinha nove preceptores, que orientavam os residentes. "Eu disse a Mary Spink: vou querer entrevistar as nove pessoas". E a Mary-Jane disse o seguinte: "Isso é seu raciocínio epidemiológico, de representatividade", por que são nove, são todos, mas são todos diferentes, e ela disse o seguinte: "Se você escolher bem um informante, basta um", pois, "ao você pegar os nove, você não fez nenhuma análise deles". Você tem que fazer uma análise deles, qual idade, sexo, quem os alunos gostam mais, etc., porque este sujeito não tem representatividade, mas a experiência/vivência dele tem significado. Dessa maneira poderá com a abordagem qualitativa, entender o significado de uma interação que você não está conseguindo interpretar.

\section{Você não tem medo de errar, quando escolhe menos?}

Em princípio, o avaliador não pode ter medo de errar. Tem é que sempre explicitar com que referências trabalha e qual o grau de incerteza está abordando um objeto complexo em saúde. Aprendi, por exemplo, na tese da Edith em que entrevistamos os nove assistentes, que depois de analisar todas as entrevistas, vi que tudo era muito repetitivo. Ao fazer a entrevista há uma tendência de que tendem a responder aquilo que você quer saber, e não revelam os detalhes que permitam captar o significativo para os sujeitos que estão envolvidos nas interações.

\section{Hoje você aprendeu como é que, a priori, consegue identificar qual seria o informante-chave mais significativo a ser entrevistado?}

Passei a entender que a abordagem qualitativa em avaliação não é uma exploração que só os antropólogos, os psicólogos, os linguistas fazem. A abordagem qualitativa é aquela forma que você vai tentar entender o empírico concreto de alguém que tem significado no seu processo, 
para você poder entender uma hipótese que você previamente formulou. Tenho complementado esta abordagem por meio de Bardin, Minayo, Malu Bosi, Rosana Onocko, cujos conhecimentos e referências tem me ajudado muito. Posiciono-me como médico, formado, bem estruturado. Não tenho a mesma capacidade de percepção de fala, de coisas, mas eu acho que entender o significado das relações por alguém que tem, pela sua experiência concreta, condições de dizer o que é importante ou não, me fez aprender que é isso que eu tenho que trabalhar.

\section{Que outros referenciais você foi construindo?}

Eu comecei a achar que o qualitativo não é para validar um dado quantitativo, é para entender outra coisa. Eu comecei a ter outro referencial, que é o Creswell, que trabalha o quanti-qualitativo sequencial. Ele não é concomitante, é para entender o significado do quantitativo para o qual eu já tenho uma hipótese. Eu exploro o quantitativo, o máximo possível, para saber como as coisas estão andando, e aí eu formulo uma hipótese do que eu quero saber da interação. Isso me permite entender melhor o quantitativo que eu analisei. Fui caminhando e lendo, inclusive, que muitos qualitativos eram para validar se aquele quantitativo era bom ou não. No quantitativo busco a lógica da representatividade dos achados. No qualitativo, retornando para Spink, busco a lógica do sujeito social construído, que é diferente da representatividade, fortemente baseada na epidemiologia.

Assim o qualitativo pode trazer um significado para aquilo que eu não consegui entender. É a partir desse momento que eu comecei achar que avaliação tem que ser quanti-quali, e que a avaliação, como eu já dizia em 2001, pode ser com poucos dados, porque tem que ter uma pergunta avaliativa, porque quem não tem a pergunta está fazendo diagnóstico. Assim o avaliador que tem a pergunta sabe o que está procurando. E o que você está procurando como avaliador não é fazer justiça, nem encontrar a verdade, e para tanto tem que correr o risco de errar. É no recorte da pergunta avaliativa que você vai cometer erros na medida que não está englobando o conjunto de seu objeto, mas com o recorte você pode afirmar mais coisas que você não poderia afirmar no conjunto. E aí, na medida que eu fui caminhando, identifiquei que a pergunta avaliativa é importante para começar, mas ela tem que gerar outras perguntas avaliativas na medida que você vai avançando no quanti-quali. Eu conseguia identificar, então, que a pergunta quali, gerada após a análise quanti, me ajuda a entender a contradição que o quanti está me mostrando. Habitualmente aquilo que o quanti está mostrando tem uma lógica básica que é a do normativo ou da percepção, ou daquilo que é senso comum. Fiquei pensando que se a avaliação realizada serve apenas com intuito diagnóstico, você estará abrindo mão de influenciar a tomada de decisão. Assim comecei achar que a avaliação para mim é um instrumento de disputa de poder, para isso eu tenho que ter clareza para onde que eu quero ir e do que eu espero alcançar com a avaliação.

\section{Sua abordagem e concepção vem mudando ao longo do tempo? Que aspectos vêm mudando? Há algum ponto de mutação?}

Sim, vem mudando com o tempo. Ao início era uma abordagem quantitativa em que se buscava analisar cada um dos três componentes, cujo limite era a dificuldade de entender o significado dos alcances e das diferenças encontradas. A partir dessa reflexão retomei o processo de construção da pergunta avaliativa que deveria ser construída com os distintos interessados na avaliação e que permitisse orientar as etapas para a análise dos componentes.

Nesse caminhar tornou-se evidente a necessidade de elaboração dos parâmetros para o processo de julgamento de valor da avaliação. Tendo identificado a importância dos parâmetros que deveriam ser aceitos pelos distintos interessados na avaliação, facilitando desta maneira que o julgamento de valor se tornasse explícito. Acho que as mudanças foram paulatinas e sucessivas resultando em mudanças nas abordagens, na escolha das metodologias e nos instrumentos.

As mudanças foram ocorrendo na medida que fui identificando as dificuldades para que as avaliações fossem oportunas nos momentos de decisão e na medida que fui entendendo melhor quem era o tomador de decisão para o qual a avaliação interessava e para que. A reflexão que fiz entre o mestrado e o doutorado foram importantes para a minha apropriação da avaliação. 0 aprendizado com a Mary-Jane Spink me desafiou no sentido de que não é só fazer entrevista, não é porque você faz grupo focal que você está fazendo uma boa abordagem, ela dizia que, tanto para grupo focal, quanto para as outras abordagens você tem que ter um informante-chave, você tem que entender que este é um indivíduo que tem experiência concreta e que você é capaz, pela sistematização,dar significado para aquilo que em princípio é individual. 


\section{E onde você se encontra hoje no tema da avaliação? Que reflexão você tem feito sobre avaliação, neste momento do tempo?}

Hoje acredito que a avaliação é um instrumento político mais do que técnico. Ele tem a função de mobilizar recursos de outros atores e instituições e não deve responder apenas às inquietudes do avaliador. Especificamente no setor saúde ,implica na necessidade de garantir que a avaliação seja quanti-quali visando impactar nos distintos interessados em avaliação no campo da saúde. A abordagem quantitativa visa impactar com mais potência nos tomadores de decisão institucionais que buscam a eficiência dos serviços e sistemas de saúde. No entanto, sendo as ações de saúde construídas na interação entre indivíduos, seja diretamente ou intermediadas por tecnologias, é crucial a utilização da abordagem qualitativa para que permita identificar os atores sociais envolvidos e as concepções que estão em jogo nas propostas de mudança implementadas no setor saúde.

Quando eu comecei a trabalhar com avaliação eu tinha uma ideia de que avaliação tinha que ser bem estruturada, e que pelas minhas experiências, seja pela pediatria, pela cultura OPAS, e tudo que a gente fez nessa década de 1970 e 1980, que eu sabia para onde e como caminhar. A partir da nossa vivência do SUS, que mudou substancialmente a nossa forma de pensar, trouxe a descentralização, acompanhado de um processo de democratização, eu comecei achar que avaliação não podia ser apenas uma etapa do planejamento, que a avaliação deveria estar cumprindo um novo papel. Por quê? Porque nessa mudança que houve a partir das normas operacionais do SUS, mas, principalmente a partir do Pacto pela Saúde, que trouxe para o bojo da saúde, a necessidade e a liberdade de definir aquilo que é possível fazer nos três níveis de gestão do SUS, diversificaram-se os interessados em avaliação. Para mim, os programas não eram mais objetivos e se tornaram imagem-objetivo. A avaliação deverá poder contemplar o processo de descentralização, o processo de compartilhamento de ações entre poderes constituídos e conflitivos e as dificuldades para organizar esse novo desenho institucional.

Eu trouxe o conflito para dentro do meu exercício avaliativo. Aquela postura de que programa diz isso, puericultura diz isso, cobertura vacinal diz isso, é uma imagem-objetivo. No SUS, após o Pacto pela Saúde, gerou-se nova diretriz: tudo está definido, mas cada um vai pactuar aquilo que se pode fazer. Por quê? Essa é a realidade concreta e precisamos pensar que seguiremos tendo problemas.

O Pacto pela Saúde me trouxe à baila o que é a realidade concreta, porque diz o seguinte: a saúde tem que ser um processo de negociação, de distintos interessados, que tem conflitos e abrangências distintas. Assim, a avaliação deve olhar a direção para onde estamos indo, analisar como estamos cumprindo os princípios de universalidade, integralidade e equidade, e o quanto todas as atividades que estão sendo implementadas pelos distintos gestores estão contemplando as necessidades da população, se estão indo na velocidade esperada e em condições de sustentabilidade. Por quê? Quando eu identifico a construção do SUS com essa complexidade e digo que as normas não são mais um nirvana, eu tenho que trabalhar uma disputa e conflitos permanentes de interesses legítimos. A disputa e o conflito não vão acabar nunca.

\section{Qual seria o maior desafio contemporâneo em avaliação de serviços no século XXI?}

O maior desafio é a identificação de para quem e para que está servindo a avaliação. Uma vez que ela tem uma base conceitual e política, ela não pode ser ingênua. A metodologia, os desenhos, os instrumentos estão muito disseminados, conhecidos e adequadamente aplicados bem como há facilidade no acesso aos dados e equipes preparadas e competentes para a coleta e análise de dados secundários e primários. No entanto, apesar do cumprimento das etapas técnicas, o maior desafio é identificar para quem e para que está sendo realizada a avaliação. Por ser um processo essencialmente político baseado em referenciais teóricos, as possibilidades de realizar a avaliação existem e são desenvolvidas em várias instâncias e por distintos sujeitos. No entanto, há necessidade de que se clareie a pergunta avaliativa, formulada por quem, e para que decisão. É imprescindível que os indicadores, os parâmetros e o juízo de valor sejam realmente direcionados à melhoria das condições de saúde da população. Mesmo que se busque aumentar a eficiência e a efetividade, deve-se evitar que sirva para validar uma decisão previamente tomada. Como é que eu minimizo o erro? É tentando deixar cada vez mais claro o objetivo da avaliação e, para tanto, ser mais seletivo nos indicadores que quero coletar e nos parâmetros que serão utilizados. 


\section{E essa coisa de minimizar o erro? O que é isso?}

Uma frase que gosto de mencionar é a seguinte: "Avaliação não serve para assustar e nem fazer justiça, nem dizer a verdade, consequentemente, ela só serve para tentar orientar um processo de tomada de decisão", que eu defino como a capacidade de mobilizar recurso. Nesse sentido, é sumamente importante entender que qualquer avaliação trará erros e terá resposta de acordo com o interessado e de acordo com as suas escolhas. Então se você sabe que a avaliação terá erros, seja pela pergunta, seja pela amostra, você tem que se preocupar em minimizá-los. Eu não tenho mais a lógica de que a avaliação só diz verdades, coisas boas e tudo certo. À avaliação persistem dificuldades, porque por mais que você aprimore, por mais que colete, sempre conterá erros. Então, a forma de tentar minimizá-los, é fazer escolhas, explicitar totalmente as hipóteses e dizer que a conclusão que você pode chegar é no máximo essa, as outras não tenho a mínima ideia.

\section{Eu tenho acompanhado suas pesquisas, e vejo você usando a abordagem de Implementation Science. Quais são suas reflexões sobre as Ciências da Implementação?}

Acho que a pesquisa interinstitucional realizada com a coordenação da UNICAMP me ajudou muito a valorizar o conceito de traçador para avaliação de serviços e sistemas de saúde. Ao mesmo tempo trouxe para a equipe a necessidade de explorar outras iniciativas para que pudéssemos aprofundar na compreensão da fragilidade dos resultados alcançados mesmo com todos os esforços despendidos. Esse foi um dos motivos que nos aproximou da ciência da implementação.

As minhas reflexões relacionadas com os desafios e as dificuldades para a implementação de programas já vinham desde a minha pesquisa de livre-docência, quando estudei o distrito da Brasilândia/SP em que utilizei como traçadora as doenças respiratórias comuns da infância. Esta escolha foi devido a que já havia uma normatização técnica que servia com parâmetro. Meu interesse na ciência da implementação aumentou com uma webconferência que eu participei, coordenada pela Zulmira Hartz ${ }^{7}$. A outra foi uma apresentação do Victor Wunsch ${ }^{8}$ apresentando pela Fapesp o edital impulsionando a ciência da implementação.

A ciência da implementação parte do pressuposto que há evidências científicas suficientes e validadas que não conseguem chegar na linha final do cuidado em saúde, por isso a necessidade de se estudar a implementação delas. Assim fui na literatura e li 12 artigos científicos, manuais da OMS, do Banco Mundial e outros, em que tive contato com distintos frameworks. Fiquei com a impressão de que: "de novo uma intelectualidade montando esquema que está dizendo que quem não fizer de uma determinada maneira não é implementação". Fui buscar uma referência e ao analisar o Consolidate Framework for Implementation Research (CFIR) (Keith et al., 2017), que trata de stakeholders, outside, inside, bem mais complexo. E daí eu pensei: outside-inside é contexto, stakeholders é interessado. Tomando como base o CFIR e os outros frameworks estudados, estou propondo utilizar quatro dimensões que me parecem a essência do estudo da implementação quais sejam: Política, Ator Social, Estratégia e Contexto.

\section{Você está em busca do que é significativo para poder interpretar as contradições, né?}

Exatamente! Porque nunca a ciência foi tão poderosa para definir a vida da gente. A ciência não é uma verdade absoluta. E você tem $1 \%$ de chance de morrer, mas, se você morrer, esta possibilidade vira 100\%! Quantos falso-negativos, falso-positivos a gente está tendo em uma mamografia? Quantos indivíduos estão tomando medicamento para diabetes e tem $95-100 \mathrm{mg} / \mathrm{ml}$ de glicemia baseado no critério definido que seria pré-diabético? Entender por que adere ou não, se incorpora outros comportamentos como exercício físico e controles da dieta são extremamente importantes. Para que se consiga entender esses comportamentos será necessário explorar, entender o significado para o usuário da doença, do risco, do tratamento. Essa abordagem qualitativa deverá ser incorporada na avaliação da implementação para que seja alcançado o resultado esperado na incorporação das evidências.

\footnotetext{
7 Licenciada em Educação pela Universidade Federal do Rio Grande do Norte (1974), com graduação em Medicina pela FESO - Rio de Janeiro (1979), mestrado e doutorado em Saúde Comunitária pela Université de Montreal (1989 e 1993) e pós-doutorado pela École Nationale de Santé Publique-France (1997). É pesquisadora titular de Epidemiologia da ENSP/Fiocruz (aposentada). Atualmente é professora catedrática e coordenadora da Unidade Curricular de Avaliação em Saúde no Programa de Doutoramento em Saúde Internacional da Universidade Nova de Lisboa, Portugal.

8 Docente da FSP/USP. Foi diretor da FSP entre 2014 e 2018.
} 
Na sua opinião, qual seria sua maior contribuição para o tema da avaliação de serviços de saúde? Qual seu escrito que você reputa como o de maior relevância?

Difícil identificar uma maior contribuição. Eu repito para mim que o que tenho de maior relevância é o livro de Avaliação do Programa de Atenção à Saúde do Adolescente: um modo de fazer. Foi com esse livro que fui fortalecendo minha linha de pesquisa e de atuação profissional. O livro permitiu que divulgasse as abordagens e que estimulasse as pessoas a realizarem mais avaliações sem medo de errarem em avaliação. Foi muito importante isso!

Os artigos publicados do mestrado, doutorado e livre-docência retratam a minha evolução na incorporação de distintas metodologias, instrumentos e planos de análise. Dos artigos que eu publiquei de metodologia quanti-quali, sequencial, com formulação de pergunta avaliativa. A tese com a minha aluna Cristiane Andrea Locatelli de Almeida, uma pesquisa de avaliação participativa que mostrou a factibilidade desta abordagem e o doutorado da Edith Lauridsen Ribeiro, em que estudamos o problema de saúde mental na atenção básica, foram trabalhos científicos publicados que expandiram os desenhos de avaliação.

Outra contribuição foi a avaliação quantitativa, trabalhando com bases de dados disponíveis, para fazer associações entre indicadores com o Marcos Drummond. Esse trabalho mostrou que, utilizando dados disponíveis (secundários) é possível responder importantes perguntas avaliativas. Outra contribuição foi usar traçadores para avaliar serviço e sistemas de saúde na busca da integralidade. Em síntese poderia apontar três eixos de contribuição no campo da saúde:

1. Metodologia de avaliação quanti-quali de serviços, sistemas e programas de saúde, partindo da análise quantitativa ampla utilizando os dados existentes no sistema de informação. A avaliação de sistemas complexos vai exigir desenvolver habilidades na utilização da base de dados disponíveis. Por exemplo, dados contraditórios entre Estrutura, Processo e Resultado são muito úteis em avaliação, de maneira semelhante aos dados de produção que são muito distantes da média, pois podem estar refletindo alguma característica que interessa na avaliação. Cabe realçar que a avaliação não deve ter preocupação em identificar causalidade, que é extremamente difícil e não é o objetivo da avaliação no campo da saúde pública.

2. Utilização da condição traçadora para analisar efetividade e integralidade da atenção à saúde. A utilização da condição traçadora para avaliar qualidade e efetividades dos serviços e sistemas de saúde eu considero uma tecnologia imprescindível para que avaliação atinja um outro patamar de reconhecimento e utilização para a melhoria das ações de saúde.

3. Sistematização da lógica da avaliação como estratégia política visando influenciar na tomada de decisão. Contribuições para incorporação no cotidiano com distintas metodologias, objetos e planos de análise permite que possamos oferecer aos profissionais de saúde, que estão na prática concreta, a possibilidade de identificar alternativas de reflexão crítica do trabalho realizado por meio da avaliação direcionada a mobilização de recursos factíveis de serem mobilizados pela avaliação.

\section{Enquanto estiver na ativa, que contribuições/legados você pretende deixar em termos de avaliação de serviços de saúde?}

Pretendo contribuir na formação de profissionais de saúde e de acadêmicos, estimulando e possibilitando que desenvolvam espírito crítico quando estiverem desenvolvendo avaliações de serviços, sistemas e tecnologias de saúde. Desejo que possam compreender e aplicar a avaliação como um instrumento político com a finalidade de disputar o poder instituído. Será importante que levem em conta que a avaliação para essa finalidade provavelmente não será capaz de influir na decisão macro política, mas poderá influir na direcionalidade e na velocidade em que as políticas de saúde estão sendo implementadas. As potenciais contribuições futuras da avaliação em saúde seriam:

- Quais pressupostos das políticas necessitam ser revistas para que possam alcançar os objetivos propostos, nos distintos níveis de atuação?

- Como os atores sociais atuam e quais os que fortalecem e fragilizam no processo de implementação? 
- Quais são as estratégias implementadas efetivas para que se alcance os objetivos propostos de melhoria na saúde da população, que não sejam a produção e produtividade da oferta?

- Quais as variáveis de contexto que fortalecem ou fragilizam a implementação das ações de saúde principalmente aquelas que influenciam diretamente nos usuários do setor saúde?

Eu quero continuar sendo capaz de formar pessoas com capacidade de construir o pensar histórico nessa construção de um sistema universal e gratuito que apesar dos avanços têm construído contradições que não têm sido capazes de minimizar as iniquidades sociais.

Gostaria que a avaliação, como um campo da ciência, possa ser um instrumento político para a construção de uma sociedade mais justa. Espero que a avaliação no campo acadêmico ou na organização de serviços e sistemas de saúde, seja um apoio importante e efetivo na tomada de decisões em políticas públicas.

Para tanto, quem trabalha com avaliação precisa fazer o tempo todo o exercício de para que e para quem estamos fazendo avaliação para tomada de decisão. Assim, para que a avaliação influencie políticas de saúde será importante considerar que não basta um bom método, não basta uma análise estatística robusta, essas podem facilitar a publicar o artigo científico, mas sem necessariamente influenciar a tomada de decisão.

Minha contribuição, enquanto estiver na ativa, será constantemente problematizar para que e para quem está servindo a avaliação. Acredito que assim contribuirei para descobrir novas abordagens e vertentes alternativas de contribuir para políticas públicas na busca da universalidade, integralidade e equidade no SUS.

\section{Fonte de financiamento}

Não há.

\section{Conflito de interesse}

Não há.

\section{Agradecimentos}

Agradecimento especial ao Professor Oswaldo Tanaka que com o coração aberto nos concedeu esta entrevista. A entrevista com o Prof. Oswaldo Tanaka foi publicada originalmente em AKERMAN, M; SANINE, P. R. (Org.) ; BAVA, M. C. C. (Org.) ; MARIN, F. A. (Org.) ; LOUVISON, M. C. P. (Org.) ; HIROOKA, L. B. (Org.) KAYANO, C. (Org.) ; MARQUES, M. C. (Org.) . ATENÇÃO BÁSICA É O CAMINHO DESMONTES, RESISTÊNCIAS E COMPROMISSOS - A RESPOSTA DO PROGRAMA DE MELHORIA DA QUALIDADE DA ATENÇÃO BÁSICA. 1a. ed. SP: HUCITEC, 2020. v. 1. e cedida com generosidade para publicação na Revista Brasileira de Avaliação por Mariana Nada, da Editora HUCITEC. A ela e aos funcionários da HUCITEC nossos mais sinceros agradecimentos.

\section{Referências}

Keith, Rosalind E., Crosson, Jesse C., O'Malley, Ann S., Cromp, DeAnn, \& Taylor, Erin Fries. Using the Consolidated Framework for Implementation Research (CFIR) to produce actionable findings: a rapidcycle evaluation approach to improving implementation. Science. 2017;12:15. Recuperado em 1 de abril de 2020, de https://implementationscience.biome dcentral.com/articles/10.1186/s13012-017-0550-7. 